\title{
TRADIÇÃO ORAL E ESCRITA LITERÁRIA: \\ O EXEMPLO DAS LITERATURAS AFRICANAS DE LÍNGUA FRANCESA
}

\author{
Vera Lucia Soares ${ }^{*}$
}

En Afrique, quand un vieillard meurt, c'est une bibliothèque qui brûle.

(Amadou Hampâté Bâ)

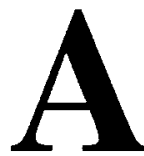

tradição oral tem sido, ao longo dos tempos, a forma predominante de transmissão da memória coletiva no continente africano, seja na África Negra, seja no Maghreb (África do Norte). É através das histórias narradas pelos mais velhos, pelos contadores de histórias ou pelos griots $^{1}$ que as crianças africanas são iniciadas nas lendas, nas crenças ancestrais, na doutrina religiosa e na própria história de seus povos.

Mesmo durante o domínio europeu, que se estendeu do século XIX a meados do século $\mathrm{XX}$, a tradição oral se manteve viva no continente. Na verdade, durante esse período ela foi "um grito de resistência e uma forma de

* Universidade Federal Fluminense.

1 Na sociedade africana tradicional, os griots pertencem a uma casta especial e são, ao mesmo tempo, contadores, poetas e músicos que têm a função de conservar e transmitir a história e a genealogia de uma grande família, ou seja, de uma etnia. 
auto-preservação dos referenciais autóctones, frente à esmagadora força do colonialismo" (Padilha, 1995, p. 17).

No que concerne à colonização francesa na África, verifica-se seu caráter fortemente assimilacionista decorrente do ideal alimentado pela política expansionista da Terceira República: o de construir uma França una e indivisível. Ideal que, na opinião do historiador Raoul Girardet, era inconciliável com a diversidade dos estatutos e das instituições dos povos agrupados sob a soberania francesa (Girardet 1972, p. 187). Mas, imbuídos desse ideal e visando a assegurar sua soberania, os franceses lançaram mão de leis e decretos com o intuito de provocar a desagregação das estruturas fundamentais dessas sociedades.

O primeiro passo foi a imposição da língua francesa e, paralelamente, a proibição do uso das línguas nacionais nos setores públicos. Consequientemente, o colonizado passa a viver numa dualidade cultural, já que o modelo ocidental que norteia sua educação na escola e sua vida pública entra em choque com as regras e valores da cultura autóctone que regem sua vida privada.

Foi nesse contexto ambíguo que surgiram as literaturas negro-africana e maghrebina de língua francesa. Embora calcadas no modelo ocidental, as primeiras obras já indicavam uma tomada de consciência da realidade colonial e denunciavam os abusos cometidos pelo colonizador. A partir daí, a questão da identidade começa a ganhar corpo e, pouco a pouco, vai-se desenvolvendo o que Mohamadou Kane chama de "sentimento da especificidade cultural africana, de uma diferença a valorizar e a salvaguardar" (Kane, 1982, p. 29).

Os escritores negro-africanos e maghrebinos vão, então, buscar subsídios para seu projeto literário de reconstrução da identidade nacional exatamente na tradição oral, transformando, assim, sua narrativa de língua francesa num espaço privilegiado de expressão da memória coletiva. Mas, como traduzir a oralidade dos relatos dos velhos contadores de história numa narrativa escrita e em língua estrangeira? Para Jacques Chevrier, este é o grande dilema com o qual se confronta o escritor colonizado que "deseja ao mesmo tempo exprimir uma sensibilidade singular e transmitir sua mensagem por meio de um código lingüístico imposto do exterior" (Chevrier, 1984, p. 127).

Apesar das dificuldades, vários desses escritores têm se empenhado em realizar esse projeto. Alguns se dedicaram a reescrever contos e lendas recolhidos junto aos habituais detentores da palavra da tradição nessas sociedades, ou seja, junto aos velhos da família, aos contadores de história e aos griots. Este'E9 o caso de Birago Diop, na África Negra, e de Marguerite Taos Amrouche, no Maghreb.

O senegalês Birago Diop dedicou-se durante anos à reescrita dos contos que ouvira de Amadou Koumba, i griot de sua família materna, contos que estão 
reunidos em duas coletâneas: Les contes d'Amadou Koumba (1947) e Les nouveaux contes d'Amadou Koumba (1958).

Quanto à argelina Marguerite Taos Amrouche, sua fonte foi a própria mãe, Fadhma Aïth Mansour, uma contadora de histórias berbere originária da região da Kabília (Argélia). Como assinala a própria Taos Amrouche, no prólogo da coletânea intitulada Le grain magique: contes, poèmes et proverbes berbères de Kabylie, ela teve a sorte de encontrar em sua mãe "uma admirável narradora" da qual diz ouvir ainda a voz inspirada pronunciar num tom de encantamento a fórmula inicial que lhes fazia penetrar como por magia no universo da lenda: "Que mon conte soit beau et se déroule comme un long fil," (Taos Amrouche 1987, p. 9).

Segundo a tradição, a arte de contar é um dom e o contador um inspirado, um eleito. Por isso, existe todo um ritual envolvendo o ato de contar. Geralmente é à noite que as sessões de contos se realizam porque, além dos corpos e espiritos já estarem repousados, a noite favorece também a aproximação dos ancestrais mortos (Chevrier, 1984, p. 191). E é através de uma fórmula mágica que o contador introduz seu público nesse "universo da lenda".

Conforme explica Taos Amrouche , além da fórmula inicial, sua mãe usava uma outra para concluir os contos - "Mon conte est comme un ruisseau, je la'i conté à des Seigneurs" indicando, assim, que "o conto devia prosseguir seu curso de boca em boca, de alma em alma, até o final dos tempos" (Taos Amrouche 1987, p. 10).

Ao reescrever esse contos berberes, Taos Amrouche manteve essas fórmulas que funcionavam como um elemento de integração entre a narradora (no caso, a sua mãe) e o seu auditório.

Já Birago Diop, elimina as fórmulas iniciais e conclusivas por considerar que a transformação do conto oral em escrito produz uma rutura irreversível na relação que une o contador a seus ouvintes (Cf. Chevrier, 1984, p. 81). No entanto, ele renova o pacto narrativo que agora passa a unir o narrador e o seu leitor, produzindo um texto que explicita os mínimos detalhes da história.

Normalmente, no conto oral, a descrição pormenorizada é desnecessária porque o contador se vale de recursos gestuais e sonoros, como a mímica, o tom da voz, a música, o ritmo. Na verdade, as sessões de contos são como encenações teatrais que, evidentemente, não podem ser reproduzidas através da escrita.

No entanto, ao reescrever esses contos ancestrais, Birago Diop e Taos Amrouche procuraram manter vivas várias marcas da oralidade tradicional. Entre elas, destacam-se os diálogos ritmados por repetições e paralelismos que marcam a progressão da intriga e que, tradicionalmente, ajudavam a sua memorização, como este extraído do conto "L'Os", reescrito por Birago Diop: 
-Où est l'os?

- L'os est là-bas.

- Samollit-il?

- Il samollit.

- Remets le couvercle et attise le feu!

E mais adiante:

- Où est l'os?

- L'os est là-bas.

- S'est-il amolli?

- Il s'est amolli.

- Laisse-le là-bas.

(Diop, 1947, p. 29 e 33)

Outra forma tradicional de oralidade recorrente na reescritura dos contos é o uso de orações curtas, muitas vezes absolutas, como se pode observar neste trecho do conto "Histoire du coffre", de Taos Amrouche:

Aucun ne sut répondre. Tous les hommes restèrent muets. Le marché se dissout. Une semaine tourna. Le jour du marché ramena le fils du roi.

(Taos Amrouche, 1987, p. 129)

Além disso, todos esses contos estão polvilhados de poemas-canções, adivinhações, litanias e, principalmente, de provérbios, aos quais o narrador tradicional - "homem que sabe dar conselhos" (Benjamin, 1994, p. 200) sempre recorre porque, colocando em evidência a sabedoria antiga, os provérbios ajudam a realçar a finalidade moral do conto que é a de "definir o lugar do homem, sua conduta moral e social e o sentido de sua existência, apoiando-se na tradição dos ancestrais" (Chevrier, 1984, p. 194).

Entretanto, não é apenas nos contos que a voz da tradição se faz ouvir dentro das literaturas negro-africana e maghrebina de língua francesa. Ela também está presente na obra romanesca de vários escritores, entre os quais, Tahar Ben Jelloun, no Maghreb, e Massa Makan Diabaté, na África Negra. 
Segundo Walter Benjamin, o que distingue o romance de todas as outras formas de prosa, como os contos e as lendas, "é que ele nem procede da tradição oral nem a alimenta" (1994, p. 201). Certamente, Benjamin referia-se ao romance tal como é concebido na cultura ocidental, porque nas literaturas africanas é justamente na tradição oral que os escritores encontram a fonte que alimenta seu projeto romanesco de reconstrução da identidade.

Massa Makan Diabaté que é, inclusive, descendente de uma casta de griots do Mali, não se contenta apenas em usar a tradição oral como fonte de sua criação romanesca, mas se propõe também a dar-lhe voz através de seus personagens.

Numa trilogia escrita por volta dos anos oitenta Le lieutenant de Kouta (1979), Le coiffeur de Kouta (1980) e Le boucher de Kouta (1982), Diabaté evoca a vida cotidiana, numa aldeia do Mali, desde o final da colonização até o início do período pós-colonial, mostrando o papel desempenhado pela tradição oral na resistência ao colonizador e, posteriormente, na contestação ao regime totalitário instaurado após a independência.

No plano da forma, esses três romances têm uma estrutura fortemente dialogal e as conversas entre os personagens, conversas que parecem não ter fim, se alimentam de elementos que remetem à oralidade tradicional, como ditados, provérbios, fórmulas estereotipadas, invocações religiosas:

- Je suis serré, Soriba! Mes affaires déclinent. Restitue-moi, sans cris ni injures, la somme que j'ai donnée à Namori pour te délivrer de sa hargne.

- Cela n'est pas en mon pouvoir! hurle le Vieux Soriba. Je suis pris, Daouda, comme une souris dans un trou sans issue. Je ne peux te rendre ton dû. Il a raison, le proverbe qui dit: "Detux oiseaux au long bec ont voulu se retirer mutuellement une brindille de l'oeil: ils se sont éborgnés." Tu parles de tes soucis d'argent, à moi qui suis encore plus démuni que toi? Eh bien, Daouda, la chèvre qui bêle n'a pas si soif que ça, puisqu'elle a encore la force de bêler. Deux pauvres s'entraider!... Allahou akbar!*

(* Allah est le plus grand).

(Diabaté, 1982, p. 22-23 - os grifos são nossos) 
Ao longo da narrativa, ouvem-se também várias vozes de personagens anônimos ou secundários que ajudam a recriar o universo tradicional africano. É, por exemplo, a voz do arauto ressoando pelas ruas:

Gens de Kouta! On m'a encore chargé la bouche de paroles. (...) Un coiffeur du nom Gabriel Touré vient de s'installer à Kouta. Il nous vient de Lomé, la perle d'Afrique. Je connais cette ville, et par l'oeuf d'autruche qui surplombe la mosquée, je jure quon ne peut mieux coiffer qu'à Lomé. (1980, p.32-33)

São ainda as vozes das comadres que tecem suas maledicências:

Alors les commères!...

Les unes disent: "De mémoire de vieille femme, quel bel exemple d'amour!" Et les autres: Elle l'a marabouté. Namori appartient à Doussouba qui tient son double. (...) $(1982$, p. 131)

Já o marroquino Tahar Ben Jelloun, em seu romance L'Enfant de sable, se propõe a resgatar a tradição oral através da própria voz narrativa, ressuscitando a figura do narrador tradicional, ou seja, desse contador de histórias que, ainda hoje, encontramos nas praças públicas de várias cidades do Maghreb.

Neste romance a história enigmática de um tal Ahmed é narrada por um contador, também misterioso, que diz possuir o diário desse personagem onde está gravado o seu terrível segredo. E, com um discurso pontilhado de imagens comuns à cultura árabe, ele convida o público a ouvi-lo para ter acesso às chaves desse segredo:

Le secret est là, dans ces pages, tissé par des syllabes et des images. (...) Ce livre mes amis, ne peut circuler ni se donner. Il ne peut être lu par des esprits innocents (...). Ce livre, je l'ai lu, je l'ai déchiffré pour de tels esprits (...). Sachez aussi que le livre a sept portes percées dans une muraille (...). Je vous donnerai au fur et à mesure les clés pour ouvrir ces portes. (Ben Jelloun, 1985, p. 12-13) 
Mas, assim como acontece normalmente nas sessões tradicionais de contos, este auditório que cerca o narrador e do qual faz parte também o leitor do romance é convidado a participar da construção da história:

\begin{abstract}
Amis, nous devons aujourd'hui nous déplacer. Nous allons vers la troisième étape (...) C'est une période que nous devons imaginer et, si vous êtes prêts à me suivre, je vous demanderai de m'aider à reconstituer cette étape dans notre histoire. Dans le livre, c'est un espace blanc, des pages nues laissées ainsi en suspens, offertes à la liberté du lecteur. A vous! (1985, p. 41-42)
\end{abstract}

E quando o contador desaparece de repente, sem ter desvendado 0 segredo de Ahmed, o auditório retoma o fio da trama e continua a tecê-la, cada um se transformando num novo contador de histórias.

A partir desses exemplos de reutilização de formas tradicionais de oralidade na escrita literária negro-africana e maghrebina de língua francesa, pode-se perceber que a tradição da palavra depositária da memória coletiva dos povos da África, de um modo geral, se mantém viva. Acreditamos, portanto, que ela continuará passando de geração em geração, talvez não mais através das histórias que circulam de boca em boca, mas através da escrita, circulando de mão em mão.

Afinal, como afirma Paul Zumthor, "a fixação pela e na escritura de uma tradição que foi oral não põe necessariamente fím a esta, nem a marginaliza de uma vez. Uma simbiose pode instaurar-se (...): o oral se escreve, o escrito se quer uma imagem do oral; de todo modo, faz-se referência à autoridade de uma voz" (1993, p. 154).

\title{
RESUMO
}

Este artigo destaca alguns exemplos de reutilização de formas tradicionais de oralidade nas literaturas de língua francesa do Maghreb e da África Negra e mostra que, ao recuperar a arte de contar histórias, seja na reescrita dos contos ancestrais, seja na sua produção romanesca, os escritores africanos transformam o texto literário num espaço privilegiado de (re)construção da memória coletiva.

Palavras-chave: literaturas africanas; oralidade; memória. 


\section{RÉSUMÉ}

Cet article relève quelques exemples de réutilisation de formes traditionnelles d'oralité dans les littératures de langue française du Maghreb et de l'Afrique Noire et montre qu'en récupérant l'art de conter des histoires, soit dans la réécriture des contes ancestraux, soit dans leur production romanesque, les écrivains africains transforment leur texte littéraire dans un espace privilégié de (re)construction de la mémoire collective.

Mots-clé: littératures africaines; oralité; mémoire.

\section{REFERÊNCIAS BIBLIOGRÁFICAS}

BENJAMIN, Walter. O Narrador: consideraçōes sobre a obra de Nikolai Leskov. In: . Obras escolhidas, v.1 (Magia e Técnica, Arte e Política). 7. ed. São Paulo:

Brasiliense, 1994. p.197-221.

BEN JELLOUN, Tahar. L'enfant de sable. Paris: Seuil, 1985.

CHEVRIER, Jacques. Littérature nègre. Paris: Armand Colin, 1984.

DIABATE, Massa Makan. Le lieutenant de Kouta. Paris: Hatier (Collection Monde Noir), 1979. Le coiffeur de Kouta. Paris: Hatier (Collection Monde Noir), 1980. . Le boucher de Kouta. Paris: Hatier (Collection Monde Noir), 1982.

DIOP, Birago. Les contes d'Amadou Koumba. Paris: Présence Africaine, 1947. . Les nouveaux contes d'Amadou Koumba. Paris: Présence Africaine, 1958.

GIRARDET, Raoul. L'idée coloniale en France: de 1871 à 1962. Paris: La Table Ronde, 1972.

KANE, Mohamadou. Roman africain et tradition. Dakar: Les Nouvelles Editions Africaines, 1982.

PADILHA, Laura Cavalcante. Entre voz e letra: o lugar da ancestralidade na ficção angolana do século XX. Niterói: EDUFF, 1995.

TAOS AMROUCHE, Marguerite. Le grain magique: contes, poèmes, proverbes berbères de Kabylie. Paris: Maspéro, 1966; Paris: La Découverte, 1987.

ZUMTHOR, Paul. A letra e a voz: a literatura medieval. São Paulo: Companhia das Letras, 1993. 